\title{
Clinical Reasoning: A 60-year-old woman with ataxia
}

Sudeepta Dandapat, MD, Shilpa Chaku, DO, and James Gilchrist, MD

Neurology ${ }^{\circledR}$ 2018;90:e1627-e1630. doi:10.1212/WNL.0000000000005410
Correspondence

Dr. Dandapat

dandapatsudeepto@

gmail.com

\section{Section 1}

\section{History and examination}

A 60-year-old woman presented to the hospital 4 days after onset of difficulty speaking. Her tongue was not moving as usual and speech was slurred. In the hospital, she had difficulty with walking, tending to fall to the left. Her medical history included irritable bowel syndrome. Stroke was suspected. MRI brain was negative except for a basilar artery tip aneurysm measuring $8 \mathrm{~mm}$ in the largest dimension. She was thought to have a small stroke not revealed on MRI and discharged home on aspirin and statin. She was brought back to the hospital 2 weeks later to treat her aneurysm but reported further decline in functional status. Her examination was inconsistent, with astasia-abasia diagnosed on gait evaluation. She was thought to have psychiatric overlay in her symptoms, her procedure was postponed, and she was sent home to follow-up with her primary medical doctor to address her symptoms with possible psychiatry referral. She had no prior psychiatric disease.

Two days later, the patient was readmitted to the hospital after repeatedly falling and injuring herself. She complained of difficulty controlling her body, voice, and swallowing. She denied weakness or sensory changes. Her symptoms were worsening. On examination, she displayed anxiety and labile mood. She had halting, dysrhythmic speech, which was fluent. She had saccadic breakdown of smooth pursuit. She occasionally flailed her legs and arms, suggesting ballismus. Her deep tendon reflexes were normal with downgoing toes. She had dysmetria on finger-nose-finger test bilaterally. She had truncal ataxia when sitting and required assistance of 2 people to stand. Gait was ataxic and wide-based. She was covered in bruises.

\section{Questions for consideration:}

1. What is the localization of the patient's problem?

2. What is the differential diagnosis? Is this likely to be psychiatric?

\section{GO TO SECTION 2}




\section{Section 2}

\section{Localization and differential diagnoses}

The patient's primary complaint is gait disturbance. According to Elble and Kattah, ${ }^{1}$ gait disorders can be divided into 3 levelshighest, middle, and lowest. Highest-level disorders involve dysfunction of the cortical-basal ganglia-thalamocortical pathways. Examples would include maladaptive gaits seen in most dementias and parkinsonism. Middle-level gait disorders are characterized by hemiparesis, spastic paraparesis, dystonia, and ataxia from dysfunction of brainstem, cerebellum, and spinal cord structures and circuits. Lower-level gait disorders involve the peripheral neuromuscular, vestibular, and visual systems, as well as deconditioning, limb contracture, and arthritis. Examination done in the sitting or supine position may provide clues (abnormal finger-nose-finger test, positional vertigo, limited range of motion of joints, reduced muscle bulk, weakness, diminished proprioception) to detection of middle- and lowerlevel gait disorders. Higher-level disorders are appreciated best on transfers, standing, and locomotion. The patient's intact mental status, strength, deep tendon reflexes, and proprioception, and the absence of aphasia or apraxia, pointed away from higher- and lower-level disorders. Her axial and appendicular ataxia displayed when supine, sitting, and standing was more consistent with a middle-level gait disorder, likely localizing to the cerebellum.

The differential should include inflammatory, infectious, toxic, neoplastic (primary vs secondary vs paraneoplastic), vascular, nutritional, and degenerative disorders. It is unlikely to be psychiatric given the patient's examination and the absence of prior psychiatric history at her age. The subacute course and progression of symptoms makes a vascular process like stroke unlikely as onset should be abrupt with step-like worsening, if any. The course is also unlikely for degenerative disease such as spinocerebellar ataxia or multisystem disease as these progress insidiously over years. Alcohol and various medications can cause cerebellar degeneration, also of an insidious, chronic nature. Neither seemed operative in this patient. Nutritional deficiencies of vitamin $\mathrm{B}_{12}$ or copper can cause subacute combined degeneration, affecting posterior columns and corticospinal tracts. This can cause deafferentation of the cortical sensory functions of joint position, leading to sensory ataxia, in which coordination is normal when vision is intact but impaired when vision is blocked. This was not present. Thiamine deficiency can cause acute ataxia as part of Wernicke encephalopathy. Wernicke encephalopathy can have an abrupt onset and subacute progression. The patient was not encephalopathic but did have nystagmus though no oculomotor paresis was seen. The Miller-Fisher variant of Guillain-Barré syndrome (GBS), seen in about $5 \%$ of GBS cases, may present with acute ataxia, though ophthalmoplegia always precedes onset of ataxia and almost all cases have absent reflexes. About half to one-third of cases will also display motor weakness. Multiple sclerosis (MS) may present with ataxia, often with a history of previous attacks. MRI brain with contrast and CSF examination should show the typical findings of MS. Neoplastic processes like cerebellar primary neoplasms compressing the vermis may present with subacute ataxia, and concomitant compression of the fourth ventricle can cause symptoms and signs of obstructive hydrocephalus. The patient's MRI did not show a mass or hydrocephalus.

\section{Question for consideration:}

1. What investigations will you order? 


\section{Section 3}

\section{Investigations}

The patient underwent another brain MRI (figure) 2 weeks after the initial MRI. It showed T2 fluid-attenuated inversion recovery hyperintensity in the bilateral cerebellum but no abnormal enhancement. Her cerebellum appeared mildly atrophic. Her toxicology screen was unremarkable. She had normal vitamin $\mathrm{B}_{12}$ at $309 \mathrm{pg} / \mathrm{mL}$ (normal >200) and low thiamine $(3 \mathrm{nmol} / \mathrm{L})$ (normal range $8-30)$ and vitamin $\mathrm{D}$ (13.2 ng/mL) (normal range 20-50) levels. She was put on thiamine replacement with no change in her clinical status.

\section{Question for consideration:}

1. What investigations will you order next to refine your diagnosis?

Figure MRI brain

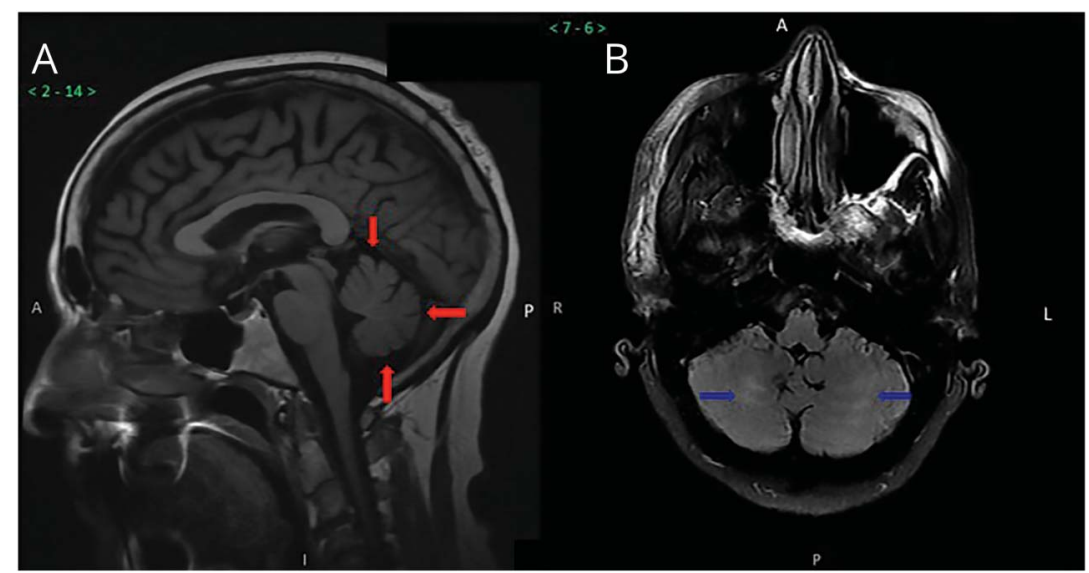

(A) Sagittal T1 shows cerebellar atrophy (red arrows). (B) T2 fluid-attenuated inversion recovery hyperintensities (blue arrows) in the bilateral cerebellar hemispheres. 


\section{Section 4}

\section{Further investigations and diagnosis}

The workup thus far had not revealed any structural or laboratory explanation for the patient's subacute ataxia except the MRI suggesting cerebellar involvement. Further history revealed she had not had a pelvic examination for 3 years, important in view of the differential diagnosis of paraneoplastic disorder secondary to gynecologic malignancy. She denied any gynecologic symptoms, with menopause attained a few years ago. She had decreased appetite and unintended weight loss. This raised suspicion for a paraneoplastic cause arising from a gynecologic cancer, such as ovarian.

$\mathrm{CT}$ of chest, abdomen, and pelvis with and without contrast showed a large ovarian mass consistent with cystadenocarcinoma with likely regional lymph node metastases. The patient's CA- 125 was elevated at 86 (normal $<35$ ) but carcinoembryonic antigen, $\alpha$-fetoprotein, and $\beta$-human chorionic gonadotropin were normal. CSF obtained concomitantly with the CT showed 7 white blood cells, lymphocyte predominant, no red blood cells, normal protein and glucose, and elevated immunoglobulin $G$ synthesis and index. Her serum and CSF paraneoplastic panel were strongly positive for Purkinje cell cytoplasmic antibodies type 1 at 1:491,520 (normal <1:240) and 1:2,048 (normal <1:2), respectively. She was diagnosed with paraneoplastic cerebellar degeneration (PCD) secondary to ovarian cystadenocarcinoma.

The patient underwent exploratory laparotomy and tissue diagnosis confirmed ovarian serous carcinoma. After tumor removal, her speech and swallowing improved. Her ataxia and labile mood did not. Postoperatively, IV immunoglobulin (IVIg) was offered but due to lack of strong evidence and insurance she elected not to treat.

\section{Discussion}

The pace of onset and progression of cerebellar ataxia provides a major clue to the etiology, as should the absence of structural defects. Acute to subacute onset of ataxia in adults has limited causes and once stroke, hemorrhage, and tumor are excluded by imaging, the differential narrows to infectious, inflammatory, toxic, nutritional, and paraneoplastic causes. CSF examination will narrow the differential further.

$\mathrm{PCD}^{2}$ is a consideration in patients in whom structural causes are absent, ovarian neoplasia suspected, and cerebellar ataxia is subacute in onset. It is usually secondary to Purkinje cell cytoplasmic antibodies type 1 . These antibodies are most commonly associated with breast, ovarian, and related Müllerian carcinomas. Even though cerebellar ataxia is the most common manifestation, in $10 \%$ of cases cerebellar signs may not be seen. It may present with or be preceded by other signs of neurologic autoimmune reaction by affecting the pyramidal tract, brainstem, anterior horn cell, and peripheral nerves. ${ }^{3}$ Cognitive impairment and personality change have also been reported.
The mainstay of treatment is finding and removing the tumor. Other potential therapies, none with good evidence or strong suggestion of benefit, include plasmapheresis, IVIg, and steroids or other immunosuppressive agents. ${ }^{4,5}$ Outcomes are not promising, as the Purkinje cell antibodies tend to destroy the reactive tissue. Previous studies have shown that cerebellar ataxias do not respond well to immunotherapy, even in patients with successful treatment of malignancies. Fewer than $10 \%$ of patients with PCD respond to immunotherapies. Candler et al. ${ }^{4}$ studied the long-term outcomes of 63 patients with paraneoplastic neurologic disease, 13 of whom had PCD. Patients received various anticancer therapies, with or without immunotherapies (IVIg, corticosteroids, or plasmapheresis). The median survival time of patients with PCD was 42 months. Three of the patients with PCD died by last follow-up. Only treatment of the tumor was found to be associated with stable or improved neurologic outcome. Keime-Guibert et al. ${ }^{5}$ studied the effects of long-term immunotherapy in 16 patients with PCD associated with anti-Hu and anti-Yo antibodies. The patients received 1 to 9 cycles of IVIg, IV methylprednisolone, and cyclophosphamide. In this study, a change in modified Rankin Scale score of at least 1 point represented clinical improvement while lack of change in modified Rankin Scale score after 3 courses of combination therapy represented stabilization. Based on these criteria, none of the 16 patients showed improvement at 4, 16, and 25 months. The median survival time for immunotherapy was 10.2 months and 14 patients died during follow-up: cancer-related in 9, neurologic in 3, and unknown in 2.5 Despite retrospective studies and case reports suggesting a benefit from immunotherapy, there continues to be a lack of prospective data showing substantial benefit. The primary cancer usually determines prognosis for survival.

\section{Author contributions}

Dr. Dandapat conceptualized and drafted the manuscript. Dr. Chaku and Dr. Gilchrist critically revised the manuscript for important intellectual content.

\section{Study funding}

No targeted funding reported.

\section{Disclosure}

The authors report no disclosures relevant to the manuscript. Go to Neurology.org/N for full disclosures.

\section{References}

1. Elble RJ, Kattah JC. Approach to the patient with gait disturbances and recurrent falls. In: Biller J, ed. Practical Neurology, 4th ed. Philadelphia: Lippincott Williams \& Wilkins; 2012:70-80.

2. Dalmau J, Rosenfeld MR. Paraneoplastic syndromes of the CNS. Lancet Neurol 2008; 7:327-340.

3. McKeon A, Tracy JA, Pittock SJ, Parisi JE, Klein CJ, Lennon VA. Purkinje cell cytoplasmic autoantibody type 1 accompaniments: the cerebellum and beyond. Arch Neurol 2011;68:1282-1289.

4. Candler PM, Hart PE, Barnett M, Weil R, Ress JH. A follow up study of patients with paraneoplastic neurological disease in the United Kingdom. J Neurol Neurosurg Psychiatry 2004;75:1411-1415.

5. Keime-Guibert F, Graus F, Fleury A, et al. Treatment of paraneoplastic neurological syndromes with antineuronal antibodies (Anti-Hu, Anti-Yo) with a combination of immunoglobulins, cyclophosphamide, and methylprednisolone. J Neurol Neurosurg Psychiatry 2000;68:479-482. 


\title{
Neurology
}

\author{
Clinical Reasoning: A 60-year-old woman with ataxia \\ Sudeepta Dandapat, Shilpa Chaku and James Gilchrist \\ Neurology 2018;90;e1627-e1630 \\ DOI 10.1212/WNL.0000000000005410
}

This information is current as of April 30, 2018

Updated Information \&
Services

References

Subspecialty Collections

Permissions \& Licensing

Reprints including high resolution figures, can be found at: http://n.neurology.org/content/90/18/e1627.full

This article cites 4 articles, 2 of which you can access for free at: http://n.neurology.org/content/90/18/e1627.full\#ref-list-1

This article, along with others on similar topics, appears in the following collection(s):

All Clinical Neurology

http://n.neurology.org/cgi/collection/all_clinical_neurology All Immunology

http://n.neurology.org/cgi/collection/all_immunology

Paraneoplastic syndrome

http://n.neurology.org/cgi/collection/paraneoplastic_syndrome

Information about reproducing this article in parts (figures,tables) or in its entirety can be found online at:

http://www.neurology.org/about/about_the_journal\#permissions

Information about ordering reprints can be found online:

http://n.neurology.org/subscribers/advertise

Neurology ${ }^{\circledR}$ is the official journal of the American Academy of Neurology. Published continuously since 1951, it is now a weekly with 48 issues per year. Copyright () 2018 American Academy of Neurology. All rights reserved. Print ISSN: 0028-3878. Online ISSN: 1526-632X.

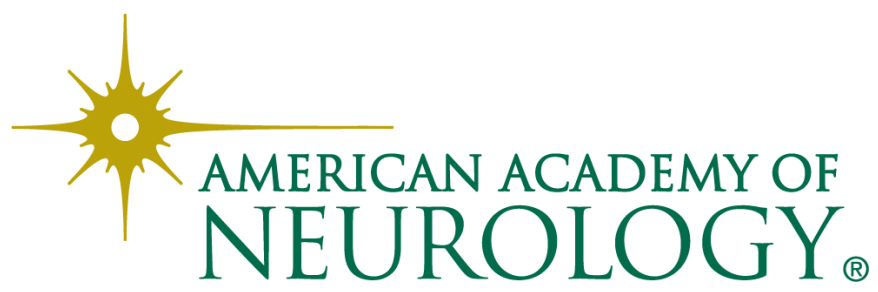

